\title{
PREVALENCE OF BLOOD PARASITES OF SOME FARM ANIMALS AT BEHERA PROVINCE
}

REDA S. FADLY

Animal Health Reasearch Insitute, Domanhour branch, Behera, Egypt.

\section{ABSTRACT}

Received: $13 / 6 / 2012$

Accepted at: 11/7/2012
Farm animals especially (cattle, buffaloes and sheep) are the main source for meat and milk prodution in Egypt. blood parasites are one of the most important and serious pathogenic protozoal disease, caused by Babesia and Theileria species which infest these animals. The aim of present work is to investigate the prevalence of blood parasites in some animals (cattle, buffaloes and sheep) by blood film examination. we examined 800 animals (300 cattle, 2 oo buffaloes and 300 sheep) aged from < one year till $>3$ years in period of April 2011 to March 2012. At Behera province. Using thin blood smears, stained with Giemsa stain and examined under microscope. It was found that 130 out of $300(43.3 \%), 40$ out of $200(20 \%)$ and 117 out of $300(39 \%)$ cattle, buffaloes and sheep were positive by microscopic examination. Then the incidence of Babesia spp. in cattle, buffaloes and sheep by blood film examination were $19.33 \% .9 \%$ and $17 \%$. while the incidence of Theileria Spp. in cattle, buffaloes and sheep by blood examination were $23 \%, 10$ $\%$ and $20 \%$. Mixed infection by Babesia spp and Theileria spp were $1 \%, 1 \%$ and $2 \%$ in cattle, buffaloes and sheep. Regarding the prevalence rate of infection in relation to age, high incidence of both parasites Babesia spp. andTheileria spp. at (2 -3 years) were $28 \%, 16 \%$ and $25 \%$ in cattle, buffaloes and sheep positive for Babesia spp. and were $30 \%, 18 \%$ and $28 \%$ in cattle, buffaloes and sheep positive for Theileria spp. by Giemsa stained blood smears examination. The peak of incidence of the blood parasites was noticed in Summer and Spring months.

Key words: Blood parasites, Babesia \& Theileria, Cattle.

\section{INTRODUCTION}

Blood parasites and their vectors are the most destructive diseases of our animal health and the biggest hinderness for successful production.

Piroplasmosis is highly fatal and has serious economic impact on livesstock. This disease is caused by protozoan parasites belonging to family Babesiidae and family Theileriidae of suborder piroplasmidae.

Babesisosis and theileriosis are of the most important and serious blood parasitic disease affecting animals in Egypt (Ashmawy, et al., 1998; Radwan and El Kelesh 2009; Mervat et al., 2010) Theilerial parasites affect a wide range of mammals mainly, ruminants and are particularly important as pathogens of domestic cattle, buffaloes, sheep and goats in the tropical and sub tropical regions.

Tropical theileriosis is sever, often fatal disease caused by Theileria annulata. The parasite is transmitted by the bite of tick from Hyalomma spp.

Diagnosis Theileria spp. infection was based on the light microscopic detection of parasite in thin blood smears and presence of schizonts in stained lymph node biopsy smears (Uilenberg, 1981).

Babesiosis is a tick born disease of domestic wild animals and humanbeing. Babesia is a small protozoan found in vertebrates red blood cells.
Perfect diagnosis is essential for successful control measures, Giemsa stained blood smears was the method of choice to detect Babesia in the blood of infected animals especially in acute cases (Salem et al., 1999).

The aim of the present work was planned to identify Theileria and Babesia Species in cattle, buffaloes and sheep and its seasonal incidence.

\section{MATERIALS and METHODS}

\section{Animals:}

A total 800 animals from private farms located in Behera Province cattle, buffaloes and sheep aged between $(<1->3$ years) were examined for the existence of blood parasites. Samples were collected from animals showed clinical signs of the disease.

\section{Samples:}

Two blood samples were collected from the juglar vein by using steril sharp needle with wide pore used for blood smear and were collected in clean and dry test tube containing EDTA as anticoagulant.

\section{Blood smear:}

Some precautions should be taken into account like using very clean, dry glass slides, clean, dry regular edges speeder slides, sharp sterile needle, and absolute methyle alcohol. 


\section{Giemsa stain stock solution:}

Giemsa powder $(0.5 \mathrm{~g})$ dissolved in glycerin absolute $(33 \mathrm{ml})$, the powder was dissolved in glycerin with vigorous shaking. Then the mixture was added to one liter methyle alcohol. The stain was transferred to a tightly stopper brown bottle and stored in dark place for two months the stain was filtered through filter paper prior to use.

\section{Blood film:}

Thin blood films were prepared and left in air to dry and fixed in absolute methyle alcohol for $1-2 \mathrm{~min}$.

Staining with freshly filtered and diluted 10\%Giemsa stain for $30-45$ minutes then washed with distal water to remove excess of stain.

The Slides were left to dry, then put one drop of cider oil examined under oil immersion lens according to (Levine, 1985).

\section{Examination of blood film for blood parasites:}

$1 / 4-1 / 2$ inch from the end of the film and transferred from one side of film to other (cross sectional method) to give constant and representative examination. Animal can be considered negative if the three slides were negative.

\section{RESULTS}

Table (1) Incidence of theileriosis and babesiosis among cattle, buffaloes and sheep ,by microscopic examination of blood smears of 800 animals (300 cattle, 200 buffaloes and 300 sheep) aged from $<1$ years until $>3$ years at the period from May 2011 until April 2012 at Behera province. Out of 300 cattle $130(43.3 \%)$ were positive for blood parasites 58 $(19.33 \%)$ positive forBabesia spp. and $69(23 \%)$ positive for Theileria spp. and mixed infection with Theileria spp. and Babesia spp. was 3(1\%), Out of 200 buffaloes $40(20 \%)$ were positive for blood parasites 18 (9\%) positive for Babesia spp., 20 (10\%) positive for Theileria spp. and mixed infection with Theileria spp. and Babesia spp. was 2(1\%). Out of 300 sheep $117(39 \%)$ were positive for blood parasites which 51(17\%) positive for Babesia spp.and 60 (20\%) positive for Theileria spp. and mixed infection with Theileria spp. and Babesia spp. was 6( 2\%) by Giemsa stained blood smears examination.

Table (2) \&Table (3) showed that the infection rate increased with age in cattle, buffaloes and sheep. The highest infection rate at age group (2-3years) were $28 \%, 16 \%$ and $25 \%$ in cattle, buffaloes and sheep positive for Babesia spp. and were $30 \%, 18 \%$ and $28 \%$ in cattle, buffaloes and sheep positive for Theileria spp. by Giemsa stained blood smears examination.

Table (4) \& Table (5) revealed that the maximal infection rate was recorded during summer and spring. The infection rates of Babesia spp. were $28 \%$ , $23 \%, 12 \%$ and $8 \%$ in summer, spring, Autumn and winter in cattle, $16 \%, 14 \%, 6 \%$ and $4 \%$ in buffaloes while it was $24 \%, 22 \%, 12 \%$ and $10 \%$ in sheep. The same relation between seasonal incidence and infection rate of Theileria spp. among cattle, buffaloes and sheep, were recorded high incidence rate of infection in summer and spring followed by Autumn and winter $30 \%, 28 \%, 16 \%$ and $12 \%$ in cattle, $18 \%, 16 \%, 6 \%$ and $4 \%$ in buffaloes while in sheep it was $28 \%, 26 \%, 16 \%$ and $8 \%$.

The positive blood smears for Babesia spp. revealed that the majority of the parasites were rounded and tend to occur peripherally in erythrocytes, while other forms (dot, ring, ovoid, single and double pear shape) were also found. The morphometric data showed the $2.8 \mathrm{u}$ is average for the round forms single pyriform was $2.8-3.8 \times 1.8-2.2 \mathrm{u}$ and double pyrifrom measured was $2.8-3.8 \times 1.8-2.2 \mathrm{u}$.

Positive blood smears for Theileria spp. showed that, the parasites was found in different morphological forms, Ring forms measured $1.3 \mathrm{u}$ was found in infected erthrocytes with high percentage. The schizonts (koch's blue bodies) were detected macroschizonts and microschizonts. Macroschizonts measured 8.5 X $3.5 \mathrm{u}$ while microschizonts measured 9.75 X 3.75 u. Figs(1) (2), (3) (4) Show morphological chreacter's of blood parasites.

Table 1: Prevalence of blood parasites in cattle, buffaloes and sheep by blood film examination at Behera province

\begin{tabular}{|c|c|c|c|c|c|c|c|c|c|}
\hline \multirow{3}{*}{$\begin{array}{c}\text { Animals } \\
\text { Cattle }\end{array}$} & \multicolumn{3}{|c|}{ Examined animals } & \multicolumn{6}{|c|}{ Parasite spp. } \\
\hline & \multirow{2}{*}{$\begin{array}{c}\text { Total } \\
300\end{array}$} & \multirow{2}{*}{$\begin{array}{l}\text { +ve } \\
130\end{array}$} & \multirow{2}{*}{$\frac{\frac{\circ}{0}}{43.3}$} & \multicolumn{2}{|c|}{$\begin{array}{c}\text { Babesia } \\
\text { spp. }\end{array}$} & \multicolumn{2}{|c|}{$\begin{array}{c}\text { Theileria } \\
\text { spp. }\end{array}$} & \multicolumn{2}{|c|}{$\begin{array}{c}\text { Mixed } \\
\text { infection }\end{array}$} \\
\hline & & & & $\begin{array}{c}+ \text { ve } \\
58\end{array}$ & $\begin{array}{c}\frac{\circ}{0} \\
19.33\end{array}$ & $\begin{array}{c}+v e \\
69\end{array}$ & $\begin{array}{l}\div \\
23\end{array}$ & $\begin{array}{c}+v e \\
3\end{array}$ & 1 \\
\hline Buffaloes & 200 & 40 & 20 & 18 & 9 & 20 & 10 & 2 & 1 \\
\hline Sheep & 300 & 117 & 39 & 51 & 17 & 60 & 20 & 6 & 2 \\
\hline
\end{tabular}


$\underline{\text { Assiut Vet. Med. J. Vol. } 58 \text { No. } 134 \text { July } 2012}$

Table 2: Prevalence of Babesia. Spp. infection among cattle, buffaloes and sheep of different age groups using blood film examination

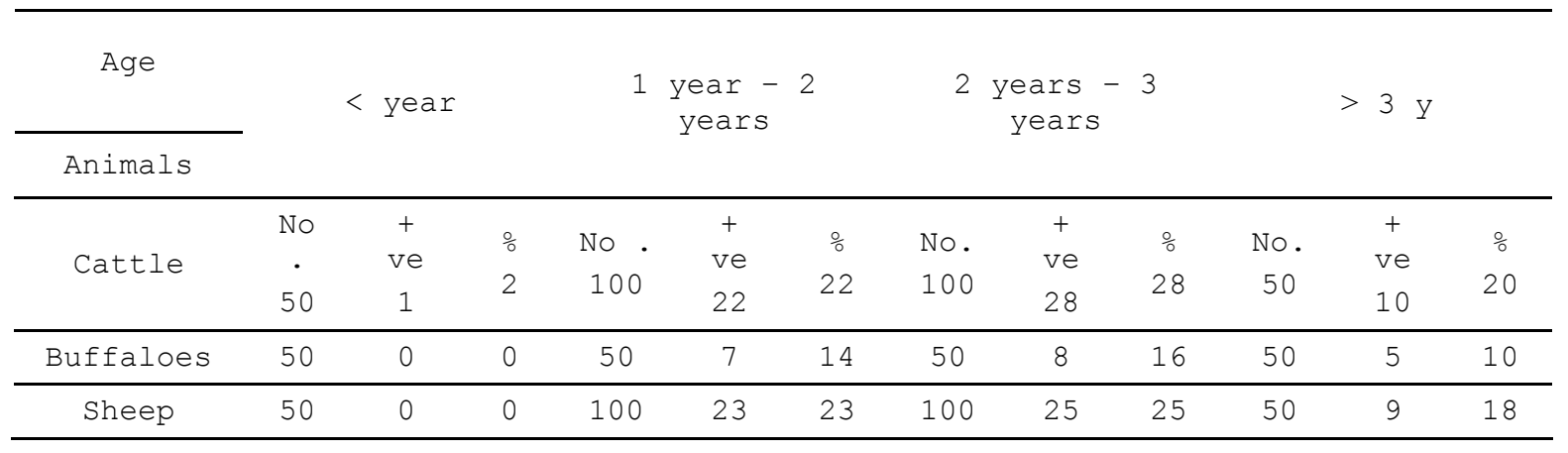

Table 3: Prevalence of Theileria spp. infection among cattle, buffaloes and sheep of different age groups using blood film examination

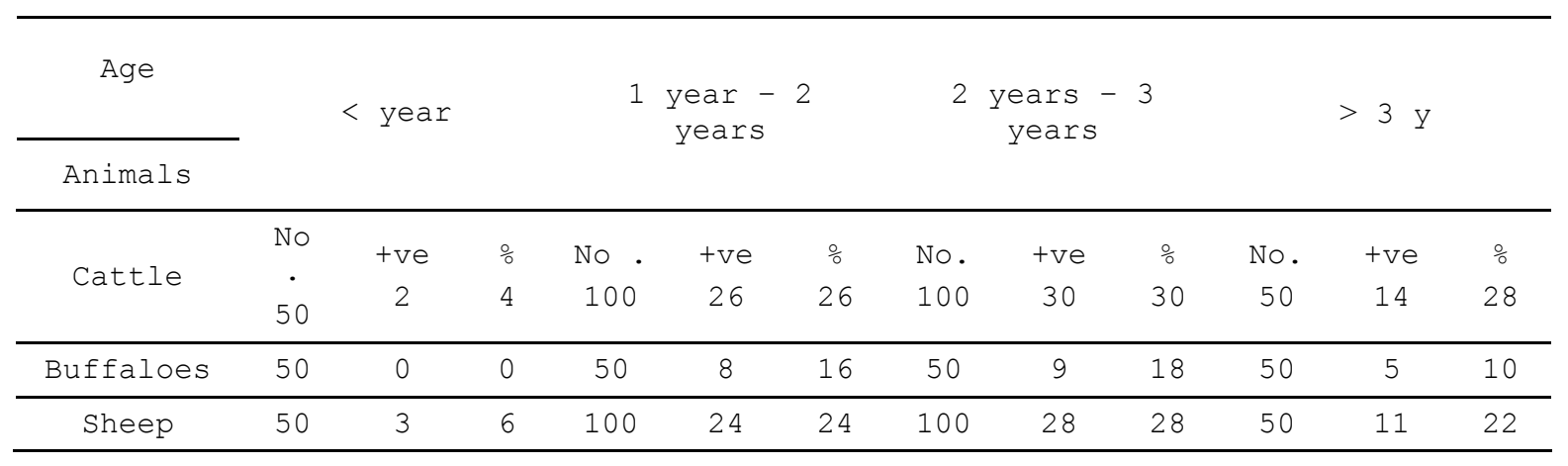

Table 4: Seasonal prevalence of Babesia Spp. in cattle, buffaloes and sheep by blood film examination at Behera province

Animals

Cattle Buffaloes Sheep

\begin{tabular}{cccccccccc} 
season & No. & +ve & $\%$ & No & +ve & $\%$ & No. & +ve & $\%$ \\
Summer & 100 & 28 & 28 & 50 & 8 & 16 & 100 & 24 & 24 \\
\hline Autumn & 50 & 6 & 12 & 50 & 3 & 6 & 50 & 6 & 12 \\
\hline Winter & 50 & 4 & 8 & 50 & 2 & 4 & 50 & 5 & 10 \\
\hline Spring & 100 & 23 & 23 & 50 & 7 & 14 & 100 & 22 & 22 \\
\hline
\end{tabular}

Table 5: Seasonal prevalence of Theileria Spp. in cattle, buffaloes and sheep by blood film examination at Behera province.

\begin{tabular}{|c|c|c|c|c|c|c|c|c|c|}
\hline Animals & \multicolumn{3}{|c|}{ Cattle } & \multicolumn{3}{|c|}{ Buffaloes } & \multicolumn{3}{|c|}{ Sheep } \\
\hline \multirow{2}{*}{ Summer } & No . & tve & 응 & No . & +ve & 응 & No. & +ve & 응 \\
\hline & 100 & 30 & 30 & 50 & 9 & 18 & 100 & 28 & 28 \\
\hline Autumn & 50 & 8 & 16 & 50 & 3 & 6 & 50 & 8 & 16 \\
\hline Winter & 50 & 6 & 12 & 50 & 2 & 4 & 50 & 4 & 8 \\
\hline Spring & 100 & 28 & 28 & 50 & 8 & 16 & 100 & 26 & 26 \\
\hline
\end{tabular}




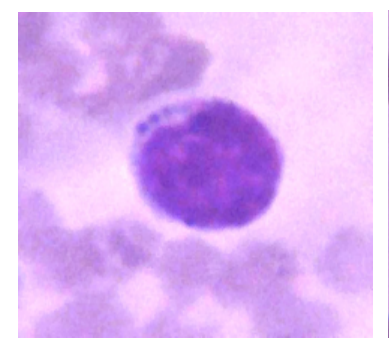

Fig (1): Macroschizont stage Fig (2): Microschizont stage in lymphocytes

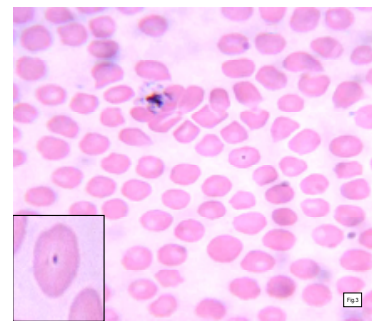

Fig (3): Erythrocytic stage of Theileria spp.

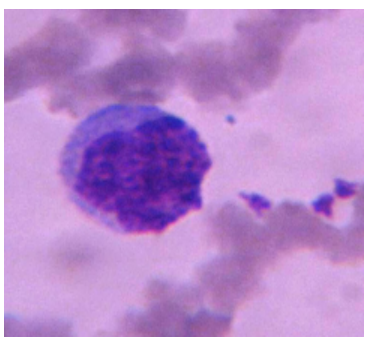
in lymphocytes

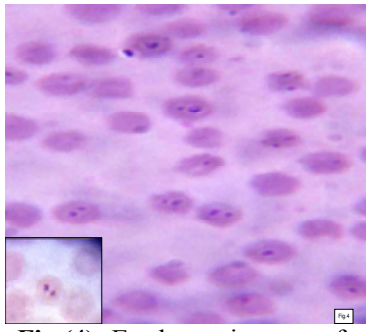

Fig (4): Erythrocytic stage of Babesia spp.

\section{DISCUSSION}

Babesiosis and Theileriosis are a tick porotozool disease that imposes large economic losses such as, drop in meat and milk production reproductive disorders, losses from deaths, costes of treatment and prevention programs (Abosakaya, 2009 and chowdhury et al., 2006) During the last 20 years human cases of Babesisosis have been reported $B$. bovis transmitted from animals to human and a human case was recorded in Egypt by (El Bahnasawy and Morsy 2008; Mazyad et al., 2010).

(Tabe 1) revealed that ( $43.3 \%, 20 \%$ and $39 \%$ ) from cattle, buffaloes and sheep were positive for blood parasites. Cattle were the highest susceptible of blood parasites, followed by sheep and buffaloes, the same result recorded by (Abdul Manan et al., 2007 and ziapour et al., 2011) This explain that tick infestation was high in cattle and sheep than buffaloes.

Prevalence of Babesia spp.revealed 19 . $33 \%, 9 \%$ and $17 \%$ in cattle buffaloes and sheep by blood smears.

In Egypt many researchers carry out a comparesion between cattle and buffaloes babesiosis and they found higher prevalence of Babesia spp. in cattle than buffaloes. Our results were $19.33 \%$ and $9 \%$ in cattle and buffaloes with regard to Egyptian studies, the results agree with, El Sawalhy (1987) in Kalubia governorate who recorded $8.7 \%$ of cattle and $1.2 \%$ of buffaloes; Gattas (1990) in Suez canal who recorded $7.26 \%$ and $5.91 \%$ incidence of Babesia spp. in cattle and buffaloes. While our results disagree with, El Ghaysh (1993) who recorded $24 \%, 5.4 \%$ in buffaloes and $12.5 \%$ and $4 \%$ in cattle in Cairo and Delta while El Badr et al. (2009) who recorded $1.9 \%$ Babesia spp . in buffaloes and $1.3 \%$ in cattle. In other counteries, Zulfiqar et al. (2012) in Pakistan reported higher incidence of Babesia in buffaloes than cattle.

The higher prevalence of Babesia spp. in cattle than buffaloes might be attributed to that cattle has longer and thick hair which allow higher tick infestation which act as avector of blood parasites (Abdul Manan et al., 2007) while the difference between our results and perivous authors may be due to climatic variation, immunological status of animals.

(Tabe 1) revealed, $17 \%$ ( 51 out of 300 ) of examined sheep harboured Babesia spp. in their blood, it was to be in agreement with Mahmoud (1992) in Beni Suef, Kafr Elsheikh, El-Fayoum and El-Shorkia governorates $(23.7 \%, 23.1 \%, 21.2 \%$ and $20.6 \%$ respectively). On the other hand, high incidence recorded by Ibrahim et al. (2000) in Egypt was 50.7\% while low incidence recorded by Ramadan and El A Kabawy (2000) in Kalubyia governorate (8.5\%).

In other countries there were different rates, Ziapour et al. (2011) in Iran found similar rate $(16.03 \%)$ while low incidence recorded by yeruham et al. (1992) In Israel, (5.56 and $7.04 \%$ ) of Babesia ovis in ewes and lambs and Savini et al. (1999) in Italy (10\%) and higher incidence recorded by Fakhar et al. (2012) in Iran found in sheep (51. 4\%).

The Variation in incidence rates of infection could be explained by the climatic condition of the area of the study that enhances the life cycle of ticks and gives higher chance to ticks to infest animals and subsequently increasing the prevalence of blood parasites. Also, Variation may be due to the immunological status of animals and different ages, different breeds and sexes.

(Table 2) The age susceptibility of Babesia spp. in present study showed that highest rate of infection at age group $2-3$ years were $(28 \%, 16 \%$ and $25 \%)$ in (cattle, buffaloes and sheep) these results agreed with that obtained by Ibrahim et al. (2000) and El Bader et al. (2009) while our results disagree with Cleon (1988) who reported that sheep aged between 6 to 12 month old have higher prevalence than animals of other age group.

The infection rate was low among young animals may be due to young calves posses innate resistance enhanced by maternal antibodies, these resistance declined gradually leaving the animal with high susceptibility to the disease.

The seasonal incidence of Babesia spp. of our study revealed that maximal infection rate was recorded during Summer months followed by Spring. These results agreed with that obtained by Gattas (1990) and Garcia et al. (2006) in large animals Ramadan and El Akabawy (2000) and Hosein et al. (2007) Fakhar et al. (2012) in sheep.

The variation on infection rates in different seasons may be attributed to the effect of climatic condition 
on the tick activity which increased in summer and spring.

(Fig 4) blood smears showed presence of Babesia spp. inside R. B .CS . Our results agree with, Reda (2001), Ali (2005) and Guerrero et al. (2007).

Typical and a typical forms of Babesia might be resulted from multiple infection and / or mutiple division sever infection with babesiosis which result in multiple invasion of erythrocytes.

Mixed infection with blood parasites include Babesia spp. and Theileria spp. which recorded in 3 cases in cattle , 2 cases in buffaloes and 6 cases in sheep ( $1 \%$, $1 \%$ and $2 \%$ ) cattle, buffaloes and sheep. Our results agree with. Nasir et al. (2000) (3.1\%) and Garcia et al. (2006) (3. $9 \%$ ), Mixed infection may attribute to exposure of animals to more than one genus of ticks or the ability of tick to transmit more than one parasite.

Mediterranean cost fever or Tropical theileriosis is a Tick born disease of (cattle, buffaloes and sheep) caused by Theileria spp. infection, extending From Morocco to china and consider one of the Major health problems.

In (Table 1), Theileria spp. was $23 \%$ in cattle by Giemsa stain blood films this result was relatively similar to Abd El Raof et al. (2000); Hoda and Osman (2009); Hosny et al. (2010) whose recorded that the incidence of theileriosis among cattle were $33.66 \% 31.16$ and $31.58 \%$. However higher prevalence rates were reported by Gamal El Dien (1993) in Behera province and El Metenawy (2000) Saudi Arabia, who recorded that theileriosis among cattle were $65.4 \%, 76.5 \%$, and $50.4 \%$ respectively and lower prevalence rates reported by El Bader et al. (2009) in South vally was $10.3 \%$.

Theileria spp. was $10 \%$ in buffaloes by Giemsa stained blood film, this percentage is relatively similar to that obtained by El Bader et al. (2009) who recorded that Theileria spp. in buffaloes was $12.5 \%$.

Theileria spp. was $20 \%$ in sheep by Giemsa stained blood film this percentage is approximately lower to those recorded in Egypt by Harfoush (2001); Kafrelsheikh, Ibrahim et al. (2000); Hala and El Kelesh (2006); Radwan and El Kelesh (2009) were $58.2 \%, 50.7 \%, 87.5 \%$ and $33.75 \%$ respectively.

These difference in prevalence may be attributed to differences in locality, sex, age, breed and climatic condition.

In (Figs 1-3) blood films revealed the presence of different forms of the Theileria spp in addatiton to koch's blue bodies. This finding is agree with perivously described by Salah and Mahran (2003); Radwan and El Kelesh (2009); Hosny et al. (2010).

In (Table 3) The age susceptibility of Theileria spp. showed that highest rate of infection at age group $2-$ 3 years were $(30 \%, 18 \%$ and $28 \%$ ) in (cattle, buffaloes and sheep). These results a greed with that obtined by Abd ElKader (1991) who reported that the susceptibility of clinical theilerosis was low among the calves of less than 1 years old then increased in age of (1 - 3 years), Anada, et al. (2009); Ziapour et al. (2011) whose recorded similar results.

The infection rate was low among young animals due to young animals posses innat resistance enhanced by maternal antibodies than This resistance declined gradually leaving the animal with high sucsptibility to disease.

In (Table 5) The seasonal incidence of Theileria Spp. of our study revealed that, the maximal infection rate was recorded during Summer and Spring months followed by Autumn and winter the results agreed with that obtained by Abd ElKader (1991) The varitation of infection rates in different seasons may attributed to effect of climatic condition on tick activity which increased in Summer as well as period of the vector activity.

\section{REFERENCS}

Abdul Manan; Khan, Z.; Ahmad, B. and Abdullah (2007): Prevalence and identification of Ixodid tick genera in Frontier Region Peshawar. Journal of Agricultural and Biological Science. 2: 21-25.

Abd El Raof, Y.M.; Ramadan, M.Y. and El Sawalhy, A.A. (2000): Clinical and some biochemical changes associated with theileriosis in buffaloes. J. Vet. Med. Res., 2: 75-84.

Abd El Kader, M.H. (1991): Studies on theileriosis in cattle and buffaloes. Thesis M. V. SC. zag. univ.

Abo Sakaya, R.Y. (2009): Some studies on Diagnosis of Bovine Babesiosis. M. V. Sc. Thesis Fac. Vet. Med. Benha. Univ .

Ali, A.M. (2005): Clinicopothological studies on Blood babesiosis with trials of treatment in cattle. M. V. Sc. thesis, clinical pathology, Fac. Vet. Med. Benha University.

Anada, J.K.; Dsouza, E.P. and Puttolakshmamma, C.G. (2009): Prevalence of Haemoprotozoan diseases in cross breed cattle in Bangalore north. Vet. worled, 2(1): 15-16.

Araffa, M. (1990): Studies on blood parasites of ruminant. M. V. Sc. Thesis, Assiut University.

Ashmowy, K.M.; Abo El Wafa, S.A. and Fadly, R.S. (1998): Incidence of Babesia bigemina infection in Native breed of cattle, Behera province, Egypt using different methods of diagnosis, Assiut. Vet. Med. J. 39(77): 110120 .

Chowdhury, S.; Hossain, M.A.; Barua, S.R. and Islam, S. (2006): Occurance of common blood parasites of cattle in Sirajgonj Sadar area of Bangladesh Bangl. J. Vet. Med. 4 (2): 143145.

Cleon, V. (1988): In "diseases of sheep" Third edition. Lea, Fembigen. Philagelphia.

El Badr, A.; Ibrahim, A.; Tolba, M.; Metwally, A.; Zaghlol, D. and Osman, A. (2009): Piroplasmosis in cattle and buffaloes in south 
valley Governorates, Egypt. EVMSPJ, 5: 8389.

El Bahnasawy, M.M. and Morsy, T.A. (2008): Egyptian Human Babesiosis in and general review. J. Egypt. Soc. Parasitol, 38: 265-272.

El Ghaysh, A.A. (1993): Studies on Babesia species infecting cattle and water buffaloes in Egypt $\mathrm{Ph}$. D. Thesis, parasitolgy, Fac. Vet. Med. Cairo University.

El Metenawy, T.M. (2000): Prevalence of blood parasites among cattle at the central area of Saudi Arabia. J. of Protozoology Research,10: 6-13.

El Sawalhy, A.A. (1987): Some studies on cattle blood parasites in Kalubia province. M.V. Sci. Thesis, Infectious diseases, Fac. Vet. Med. Zagazig University.

Fakhar, M.; Hajhasani, A.; Maroufigs; Alizadeh, H.; Shirzad, H.; Piri, F. and Pahghehs, A. (2012): An epidemiological survey on bovine and ovine babesiosis in kurdiston province western Iran. Trop. Anim. Health prod., 44 : 319- 322.

Gamal, El dien (1993): Studies on Theileria protozoan among cattle in Behera province. ph. D. thesis, Fac. Vet. Med., Alex. Univ.

Gattas, M.W. (1990): Further studies on the biological aspet of Babesia species among cattle in South Canal zone with special references to their control. Ph. D. Thesis ,Parasitology, Fac. Vet. Med. Cairo University.

Garcia, S.J.; Nagore, D.; Garcia. Perez. A.; Juste, R. and Hurtado, A. (2006): Molecular diagnosis of Theileria and Babesia species infecting cattle in Northern spain using reveres line blot macroarrays. BMC veterninary research 2:1-7.

Guerrero, F.D.; Bendel, K.G.; Davey, R.B. and Georh, J.E. (2007): Detection of Babesia bigemina infection in strains of Ripicephalus Boophuilus microplus collected from out breaks in south Texas. Vet. Parasitol., 145: 156-163.

Hala, H.W. and El-Kelesh, E.A. (2006): Haematological and Biochemical Changes in blood of Sheep suffering from Theileria infection.Egypt. J. Animal and Poultry Management, 1 (1): 201-217.

Harfoush, M.A. (2001): Some studies on blood parasites in both cattle and tick vector 6th SCI. Cong. Egyptian society for cattle diseases 4-6 November, Assiut, Egypt.

Hoda, I.M.G. and Osman, F.A. (2009): Clinical, Hematological and some biochemical Studies on cattle naturally infected with Theileria species in Assiut governorate, EVMSPJ 5: 101-113.

Hosein, I.H.; Samia, A.A.; Ibrahim, A.F.; Abou. El Nage, R.T.; Gebely, A.M. and Mona, A.M. (2007): Sero prevalence of Babesia ovis in small ruminants in Siwa Oasis, Egypt. B.S Vet. Med. J. 17: 19-24.

Hosny, M.A.; Aly, A.S. and Ahmed, O. (2010): Oxidative stress and some Haematobiochemical changes in blood of cattle during theileriosis Assiut. Vet. Med. J., 56: 218-238.

Ibrahim, M.S.; El Seify, M.A.; Hafez, A.M.; Deghidy, N.S. and Harfoush, M.A. (2000): Studies on blood parasites in sheep. The 1st scientific congress for provincial laboratonries May 15-7.

Kamani, J.; Sannusi, A.; Egwu, K.O.; Dogo, IG.; Tanko, J.T.; Kemzo, S.; Tafarki, E.A. and Gbise, S.D. (2010): Prevalence and significance of Harmoparasitic infections of cattle in North central, Nigeria. Vet. word., 3(10): 445-448.

Levine, N.D. (1985): Veterinary Protozoology. Iowa State Univ. Press pp. 365.

Mahmoud, M.S. (1992): Some serological studies on Babesia species infecting sheep in Egypt M.V. Sc. Thesis,Fac. Vet. Med. Cairo Univ., Egypt.

Mazyad, M.A.; Shoukry, M.N. and Elafy, M.N. (2010): Efficacy of Ixodes Ricinus as avector of zoonotic Babesisis in Sinai Peninsula, Egypt. J. Egypt. Soc Parasitol. 40: 499-514.

Mervat, E.l.; Ola, F.A. and Ali, M.A. (2010): Cattle babesiosis and associated biochemical alteration in Kalubyia Governorate Nature and science: 8(3) 29-32.

Nasir, A.A.; Hashmi, A.H. and Afzal, M. (2000): Prevalence of Haemoparasites in Exotic cattle. Int. Agri. B; 01, 4: 402- 403.

Radwan, I.G.H. and El-Kelesh, E.A. (2009): Identification of Theileria species in sheep and goats by ploymerase chain reaction (PCR) .Kafrelsheikh,Vet. Med. J., 3rd Sci. Congress. 10-12 May 2009, pp. 460-473.

Ramadan, M.Y. and El-Akabawy, M.L. (2000): Studies on sheep Babesiosis in Kalubyia governorate, Egypt. Minufiya Vet. J., 1: 147155.

Reda, S.F. (2001): Blood parasites of sheep At Behera province. Ph. Thesis, Fac. Vet. Med. Alex. University.

Salah, M.A. and Maharan, O.M. (2003): Parasitological and biochemical studies on tropical theileriosis in neonatal friesian calves in the Egyptian Oases Assiut Vet. Med. 49 (99): 156-176.

Salem, G.H.; Liu, X.; Johnsrude, J.D.; Dame, J.B. and Roman, R.G. (1999): Development and evalution of an extra - chromosomal DNA Based PCR test for diagnosis of bovine Babesiosis. Mol. cell probes, 13(2): 107 - 130.

Smeenk, I.; Kelly, P.J.; Wray, K.; Musuka, G.; Trees, A.J. and Jongejan, F. (2000): Babesia bovis and $B$. bigemina DNA detected in cattle and ticks from Zimbabwe by polymerase chain reaction J.S. Afr Vet. Assoc, 71(1): 21-4.

Savin, I.G.; Conte, A.; Semproni, G. and Scaramozzino, P. (1999): Tick borne diseases in ruminants of Central and Southern Italy: Epidemiology and case reports. Parassitologia, 41 (1): 95-100.

Uilenberg, G. (1981): Theilerial species of domestic livestock. In: Irvin A.D., Cunningham M.P., 
Young, A.S. (Eds.), Advances in the Control of Theileriosis. Martinus Nijhoff Publishers, The Hague, pp. 4-37.

Yeruham, I.; Hadani, A.; Gafker, F.; Rosen, S.H. and Schlien, J. (1992): A field tudy of haemoparasites in twoflocks of sheep in Israel. Isr. J. Vet. Med., 47 (3): 107-111.

Ziapour, P.S.; Esfandiari, B. and Youssefi, R.M. (2011): Study of prevalence of Babesiosis in domesticated animals with suspected signs in
Mazandaran province, North of Iran, during 2008. J. Anim. Vet. Adv., 10 (6): 712-714.

Zulfiqar, S.; Shahnawaz, S.; Ali, M.; Bhutta, A.; Iqbal, S.; Hayat, S.; Qadir, S.; Latif, M.; Kiran, N.; Ali, M. and Iqbal, F. (2012): Detection of Babesia bovis in blood samples and its effect on the hematological and serum biochemical profile in large ruminants from Southern Punjab. Asian Pacific Journal of Tropical Biomedicine: 104-108.

\section{انتشار طقيليات الام في بعض حيوانات المزرعة بمحافظة البحيرة}

$$
\text { رضا سعبر أحد فضلي }
$$

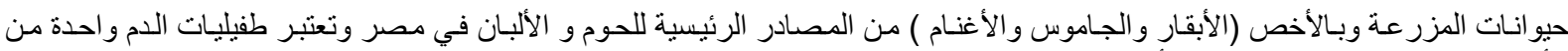

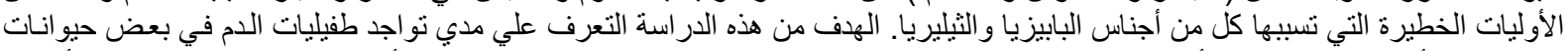

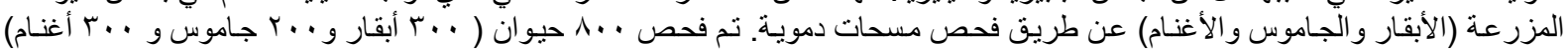

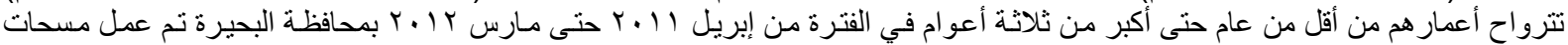

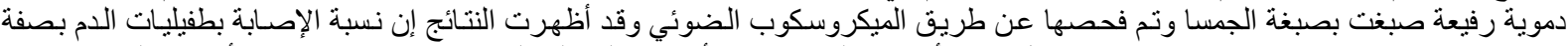

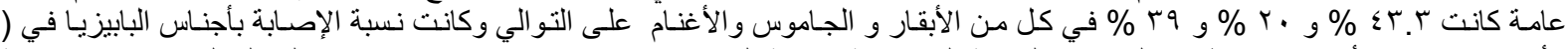

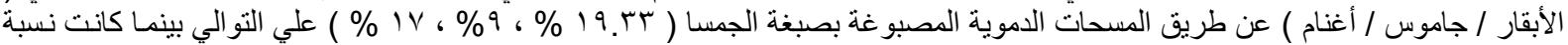

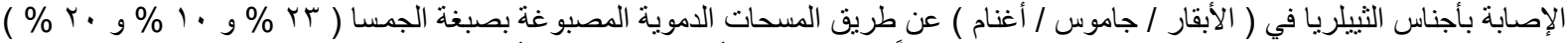

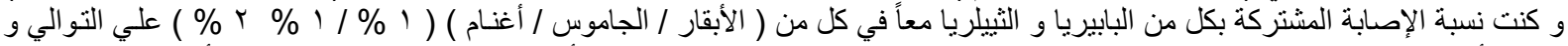

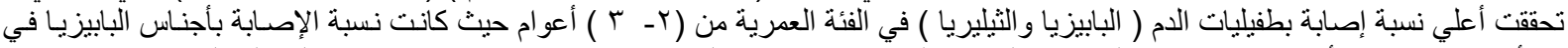

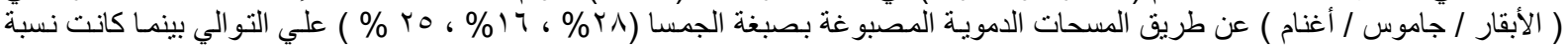

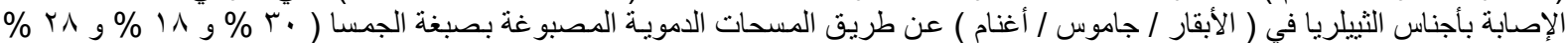

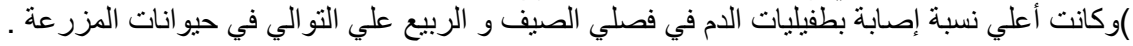

